\title{
Estresse osmótico na germinação de sementes de Petiveria alliacea L.
}

LAVEZO, A ${ }^{*}$; BRAGA, L.F.2; BATISTÃO, A.C. ${ }^{2}$; BONFANTE, L.V. ${ }^{2}$

${ }_{1}$ Universidade do Estado de Mato Grosso - UNEMAT, Avenida Pioneiro Odílio de Paula, $n$ 23, Setor HJ, CEP:78580-000- Alta Floresta - Mato Grosso - Brasil. 2Universidade do Estado de Mato Grosso - UNEMAT, Avenida Perimetral Rogério Silva s/n, Jardim Flamboyant, CEP:78580-000-Alta Floresta - Mato Grosso - Brasil

*Autor para correspondência: a.lavezo@hotmail.com

\begin{abstract}
RESUMO: O trabalho teve como objetivo verificar os efeitos dos estresses hídrico e salino na germinação de sementes de Petiveria alliacea, bem como definir os limites máximos de tolerância da espécie a esses estresses. As sementes foram submetidas aos agentes osmóticos $\mathrm{NaCl}$, $\mathrm{CaCl}_{2}$ e PEG nos potenciais à $0 ;-0,1 ;-0,2 ;-0,3 ;-0,4 ;-0,5 ;-0,6 ;-0,7 ;-0,8 ;-0,9$ e $-1,0 \mathrm{MPa}$ sob temperatura constante de $25^{\circ} \mathrm{C}$ e fotoperíodo de 12 horas, com avaliações diárias durante 30 dias. As variáveis analisadas foram porcentagem de germinação, índice de velocidade de germinação, tempo médio de germinação, índice de sincronização e frequência relativa da germinação. As sementes de $P$. alliacea sob estresse osmótico apresentam menor porcentagem e velocidade de germinação com a redução dos potencias osmóticos, principalmente com $\mathrm{CaCl}_{2}$. Em potenciais osmóticos mais negativos que -0,4; -0,5 e -0,7 MPa, respectivamente nos agentes $\mathrm{CaCl}_{2}, \mathrm{NaCl}$, e PEG, não ocorre germinação. O padrão de distribuição da frequência relativa aumentou a polimodalidade, o tempo médio de germinação e o índice de sincronização da germinação com a redução dos potencias osmóticos.
\end{abstract}

Palavras-chave: estresse hídrico, estresse salino, planta medicinal, guiné.

\begin{abstract}
Osmotic stress on seed germination of Petiveria alliacea $L$. The study aimed to investigate the effects of water and salt stress on seed germination of Petiveria alliacea, as well as to define the limits of tolerance of the species to these stresses. The seeds were subjected to osmotic agents $\mathrm{NaCl}, \mathrm{CaCl}_{2}$ and PEG in the potential $0 ;-0.1 ;-0.2 ;-0.3 ;-0.4 ;-0.5$; $-0.6 ;-0.7 ;-0.8 ;-0.9$ and $-1.0 \mathrm{MPa}$ at a constant temperature of $25^{\circ} \mathrm{C}$ and a photoperiod of 12 hours, with daily assessments for 30 days. The variables studied were germination percentage, germination velocity index, middle fear germination, synchronization index and relative frequency of germination. The seeds of $P$. alliacea under osmotic stress had lower percentage and speed of germination with the reduction of the the osmotic potential, especially with $\mathrm{CaCl}_{2}$. At more negative osmotic potentials than $-0.4 ;-0.5$ and $-0.7 \mathrm{MPa}$, respectively in the $\mathrm{CaCl}_{2}, \mathrm{NaCl}$, and PEG agents, the germination does not occur. The distribution pattern of the relative frequency increased the several modalities, , the average time of germination and the germination index of synchronization with the reduction of osmotic potential.
\end{abstract}

Keywords: water stress, salt stress, medicinal specie, guiné.

\section{INTRODUÇÃO}

Petiveria alliacea L., pertencente à família Phytolaccaceae, é um arbusto herbáceo de aproximadamente $1 \mathrm{~m}$ de altura, perene, sublenhoso, delgado e ereto, nativo da floresta Amazônica e das áreas tropicais da América do Sul e Central, Caribe e África (Camargo, 2007).

$\mathrm{Na}$ medicina popular a guiné, como a espécie é popurlamente conhecida, é utilizada para o tratamento de uma ampla variedade de distúrbios na saúde humana (Kim et al., 2006); além de ser utilizada para fins ornamentais (Cano \& Volpato, 2004), apresentando também efeito inseticida e nematicida (Gupta, 1995).

Devido à importância de utilização e exploração de $P$. Alliacea, o conhecimento dos fatores que controlam a germinação das sementes pode gerar alternativas para futuras estratégias de manejo da espécie. 
O conhecimento sobre como o estresse influencia na germinação de sementes tem importância especial na ecofisiologia para avaliar os limites de tolerância e capacidade de adaptação das espécies (Larcher, 2000). Além disso, de acordo com Rosa et al. (2005) a capacidade das sementes de algumas espécies em germinar sob condições de estresse confere vantagens ecológicas em relação a outras espécies que são sensíveis ao estresse.

A germinação das sementes é caracterizada pela reativação do metabolismo paralisado após a maturidade fisiológica e pode ser afetado por fatores internos, externos ou ambientais (Carvalho \& Nakagawa, 2000). Dentre os fatores que afetam a germinação, a água é, sem dúvida, o mais importante. Quando removida, abaixo do limite suportado pela célula, pode promover o aumento da concentração dos solutos, alteração do pH da solução intracelular, aceleração de reações degenerativas, desnaturação de proteínas e perda da integridade das membranas (Sun \& Leopold, 1997).

A disponibilidade da água afeta diretamente a germinação de sementes (Marcos Filho, 2005), sendo que a água é disponível exclusivamente por diferença de potencial hídrico entre o interior da semente e meio exterior em que ela se encontra (Cardoso, 2004).

Pereira et al. (2012) relataram que o déficit hídrico é um dos principais fatores limitantes do processo germinativo, sendo que para cada espécie existe um valor de potencial hídrico externo abaixo do qual a germinação não ocorre. Soluções salinas promovem o déficit hídrico retendo água, reduzindo o potencial hídrico, tornando a água menos acessível às plantas (Nasr et al., 2011), além de deixar o meio externo com alta concentração de sais, os quais presentes nas células podem inativar as enzimas e inibir a síntese proteica (Taiz \& Zeiger, 2004).

De acordo com Larcher (2000) a resistência à salinidade é descrita como a habilidade de evitar, por meio de uma regulação salina, que excessivas quantidades de sal provenientes do substrato alcancem o protoplasma e também, de tolerar os efeitos tóxicos e osmóticos associados ao aumento da concentração de sais.

O efeito da redução dos potenciais osmóticos sobre as sementes e plântulas depende da qualidade inicial das sementes, do tipo de sal e sua concentração (Moraes \& Menezes, 2003).

O estresse hídrico pode limitar a germinação e o desenvolvimento de diversas espécies, a adaptação às condições de estresse resulta em eventos integrados que ocorrem em vários níveis, envolvendo modificações morfológicas, anatômicas, celulares, bioquímicas e moleculares (Nogueira et al., 2005). Essas modificações variam com a espécie e o estádio de desenvolvimento da mesma, assim como com o tipo de estresse, a duração e a intensidade do mesmo (Larcher, 2000).

Para simular condições de déficit hídrico tem sido utilizado o polietileno glicol (PEG) como agente osmótico, o qual simula o estresse hídrico nas sementes sem provocar toxidez, por não penetrar nas células e não ser degradado, devido ao seu alto peso molecular (Villela et al. 1991). Soluções salinas de $\mathrm{CaCl}_{2}$ e $\mathrm{NaCl}$ também podem ser utilizadas para simular o estresse hídrico, mas podem provocar toxidez nas sementes em altas concentrações.

Este trabalho teve como objetivo verificar os efeitos dos estresses hídrico e salino na germinação de sementes de Petiveria alliacea L., bem como definir os limites máximos de tolerância a esses estresses.

\section{MATERIAL E MÉTODOS}

O trabalho foi realizado no Laboratório de Ecofisiologia e Propagação de Plantas, na Universidade do Estado de Mato Grosso, Alta Floresta - MT, sendo utilizadas sementes de Petiveria alliacea Linnaeus (Phytolaccaceae) (guiné) obtidas durante o ano de $2012 \mathrm{em}$ plantas existentes na região urbana de Alta Floresta - MT, município situado a $09^{\circ} 53^{\prime} 18.07^{\prime \prime}$ S, 5605'05.88" W e 289,89 $\mathrm{m}$ de altitude, sendo os testes realizados logo após a coleta.

As sementes coletadas foram selecionadas e, realizada assepsia superficial mediante a imersão em solução de hipoclorito de sódio $2 \%$ por 5 minutos, seguida de lavagem em água destilada. Após, as sementes foram tratadas com o fungicida Ridomil ${ }^{\otimes}$ (Metalaxil) a 0,5\% da massa de cada amostra.

O experimento foi realizado em delineamento inteiramente casualizado em esquema fatorial $3 x$ 11 (agentes osmóticos $\mathrm{x}$ potenciais osmóticos) totalizando 33 tratamentos com quatro repetições de 25 sementes.

Para avaliar o comportamento da espécie, as sementes foram expostas aos agentes osmóticos, polietileno glicol 6000 (PEG), $\mathrm{NaCl}$ e $\mathrm{CaCl}_{2}$ nos potenciais 0 (controle); $-0,1 ;-0,2 ;-0,3 ;-0,4 ;-0,5$; $-0,6 ;-0,7 ;-0,8 ;-0,9 ;-1,0 \mathrm{MPa}$, sendo as soluções de PEG preparadas a partir de Vilella et al. (1991) e para o estresse salino pela equação de Vant'Hoff, citada por Braga et al. (1999).

Para a realização dos testes as sementes foram colocadas em caixas plásticas transparentes $(11 \times 11 \times 4 \mathrm{~cm})$ sobre uma folha de papel mataborrão com $12 \mathrm{~mL}$ de cada uma das soluções, na temperatura constante de $25^{\circ} \mathrm{C}$ e fotoperíodo de 12 horas. As soluções de PEG 6000 foram trocadas todos os dias para manutenção do potencial hídrico. 
As avaliações foram realizadas diariamente durante 30 dias.

Foram avaliadas as seguintes características para determinar o potencial físico e fisiológico das sementes:

a) Grau de umidade-Realizado previamente aos tratamentos, utilizando o método da estufa a $105 \pm 3^{\circ} \mathrm{C}$, durante 24 horas, segundo as Regras para Análise de Sementes (Brasil, 2009), utilizando duas repetições de 20 sementes. Os resultados do grau de umidade (base úmida) foram expressos em porcentagem.

b) Porcentagem de germinação Utilizou-se como critério a emissão de raiz primária com comprimento igual a $2 \mathrm{~mm}$ (Rehman et al., 1996). Os cálculos foram realizados de acordo com Labouriau \& Valadares (1976), segundo a fórmula abaixo:

$$
\begin{gathered}
G(\%)=\left(\frac{N}{A}\right) X 100 \quad \text { onde: } \quad \mathrm{N}=\text { Número de sementes germinadas } \\
\mathrm{A}=\text { número total de sementes } .
\end{gathered}
$$

c) Índice de velocidade de germinação (IVG) - Foi realizado em conjunto com o teste de germinação, o IVG para cada subamostra foi obtido segundo a fórmula proposta por Maguire (1962), apresentada a seguir:

$$
I V G=\frac{N_{1}}{D_{1}}+\frac{N_{2}}{D_{2}}+\ldots \ldots+\frac{N_{n}}{D_{n}} \quad \begin{aligned}
& \text { onde: } \mathrm{N}_{1: \mathrm{n}}=\text { número de plântulas germinadas no dia } 1, \ldots ., \mathrm{n} ; \\
& \mathrm{D}_{1: \mathrm{n}}=\text { dias para ocorrência da germinação. }
\end{aligned}
$$

d) Tempo médio de germinação (TMG)

- Obtido pela equação proposta por Labouriau \&
Valadares (1976), com os resultados expressos em dias:

$$
T M G=\frac{\left(\sum n i t i\right)}{\sum \dot{n}} \quad \begin{aligned}
& \text { onde: } \mathrm{ni}=\text { número de sementes germinadas por dia; } \\
& \text { ti }=\text { tempo da avaliação depois do início do teste; }
\end{aligned}
$$

e) Frequência relativa de germinação Cálculos realizados através da contagem diária da germinação, conforme fórmula citada por Labouriau \& Valadares (1976):

$$
\begin{gathered}
F r=\frac{n i}{\sum n i} \quad \text { onde: } \mathrm{Fr}=\text { freqüência relativa de germinação; } \\
\text { ni }=\text { número de sementes germinadas por dia; } \\
\Sigma_{\mathrm{ni}}=\text { número total de sementes germinadas }
\end{gathered}
$$

f) Índice de sincronização - Cálculos realizados através da frequência relativa de germinação, conforme formula citada por Labouriau \& Pacheco (1978):

$$
\begin{array}{ll}
\overline{\mathrm{E}}=-\sum F r \log _{2} F r & \text { onde: } \overline{\mathrm{E}}=\text { índice de sincronização; } \\
& \mathrm{Fr}=\text { freqüência relativa de germinação; } \\
& \text { Log } 2=\text { logaritmo na base } 2 .
\end{array}
$$

Os tratamentos foram submetidos à análise de variância e as médias dos tratamentos foram comparadas pelo teste de Tukey, ao nível de $5 \%$ de probabilidade e por regressão polinomial, utilizando o programa computacional SISVAR (Ferreira, 2011).

\section{RESULTADOS E DISCUSSÃO}

As sementes de Petiveria alliacea apresentaram $21,4 \%$ de umidade, teor de água em que, de acordo com Carvalho \& Nakagawa (2000), há elevada respiração o que pode causar 
perda do vigor e eventuais quedas na germinação. Contudo, considerando os resultados de 97 a $99 \%$ de germinação no tratamento controle $(0 \mathrm{MPa})$ (Tabela 1) o teor de água inicial não representou um fator que interferiu na germinação das sementes.

Para a porcentagem de germinação observou-se interação entre os agentes e os potenciais osmóticos analisados (Tabela 1), não ocorrendo diferença estatística até os potenciais de $-0,1 ;-0,2$ e $-0,5 \mathrm{MPa}$ respectivamente para os agentes osmóticos $\mathrm{CaCl}_{2}, \mathrm{NaCl}$ e PEG, ocorrendo menor tolerância ao estresse quando as sementes foram expostas aos sais $\mathrm{CaCl}_{2}$ e $\mathrm{NaCl}$.

Dickman et al. (2005), também relataram que o sal $\mathrm{CaCl}_{2}$ apresentou um efeito inibitório mais acentuado que o $\mathrm{NaCl}$ na germinação de sementes de Helianthus annuus L.

Para o agente osmótico $\mathrm{NaCl}$, potenciais mais negativos que $-0,2 \mathrm{MPa}$ afetaram significativamente o potencial germinativo de $P$. alliacea resultando em redução de $78 \%$ da porcentagem de germinação no potencial à -0,4 MPa menor do que o controle, sendo que a partir do potencial à $-0,5 \mathrm{MPa}$ não ocorreu germinação.

A ausência de germinação a partir de $-0,5$ $\mathrm{MPa}$ de $\mathrm{NaCl}$ também foi relatada para sementes de Ruta graveolens L. (Yamashita et al., 2009).

Os potenciais à $-0,2$ e $-0,3 \mathrm{MPa}$ de $\mathrm{CaCl}_{2}$ afetaram significativamente o processo germinativo, reduzindo 50 e $65 \%$ respectivamente a germinação, a menos do que o controle, sendo a germinação inibida a partir do potencial à $-0,4 \mathrm{MPa}$.

Com o agente osmótico PEG observa-se redução de $28 \%$ da porcentagem de germinação no potencial à $-0,6 \mathrm{MPa}$ menor do que controle. Nos potenciais mais negativos que $-0,6 \mathrm{MPa}$ a porcentagem de germinação $P$. alliacea L. foi inibida. Pode se observar que nos resultados que $P$. alliacea é mais tolerante ao estresse hídrico do que ao estresse salino.

Estes resultados diferem dos obtidos por Sousa et al. (2008) que observaram que as sementes de Plantago ovata Forsk. suportariam mais o estresse salino que o estresse hídrico, tendo verificado decréscimo significativo da porcentagem de germinação com potenciais a partir de $-0,4 \mathrm{MPa}$ de $\mathrm{NaCl}$ e $\mathrm{CaCl}_{2}$ e -0,2 de PEG. Do mesmo modo, Fanti et al. (2004) observaram que para a espécie Chorisia speciosa St. Hil., a faixa de tolerância ao estresse salino proporcionado por $\mathrm{NaCl}$ e $\mathrm{CaCl}_{2}$ foi respectivamente entre $-1,2$ e $-1,4 \mathrm{MPa}$, superior ao estresse hídrico simulado por PEG 6000 , estando o limite máximo entre $-0,4$ e -0,5MPa.

O limite de tolerância da espécie $P$. alliacea ao estresse hídrico promovido por soluções de PEG ocorreu entre -0,6 e -0,7 MPa, semelhante ao

TABELA 1. Porcentagem e índice de velocidade de germinação (IVG) de sementes de Petiveria alliacea L. expostas a diferentes agentes e potenciais osmóticos.

\begin{tabular}{|c|c|c|c|c|c|c|c|c|c|c|c|c|}
\hline \multirow{3}{*}{$\begin{array}{l}\text { Poten. osmótico } \\
\text { (MPa) } \\
0\end{array}$} & \multicolumn{4}{|c|}{ Germinação' (\%) } & & & \multicolumn{4}{|l|}{ IVG $^{1}$} & \multirow{2}{*}{\multicolumn{2}{|c|}{ PEG }} \\
\hline & \multicolumn{2}{|c|}{$\mathrm{NaCl}$} & \multicolumn{2}{|c|}{$\mathrm{CaCl}_{2}$} & \multicolumn{2}{|c|}{ PEG } & \multicolumn{2}{|l|}{$\mathrm{NaCl}$} & \multicolumn{2}{|l|}{$\mathrm{CaCl}_{2}$} & & \\
\hline & 98 & $\mathrm{Aa}$ & 98 & $\mathrm{Aa}$ & 98 & $\mathrm{Aa}$ & 3,03 & $\mathrm{Aa}$ & 3,03 & $\mathrm{Aa}$ & 3,03 & $\mathrm{ABa}$ \\
\hline$-0,1$ & 99 & $\mathrm{Aa}$ & 94 & $\mathrm{Aa}$ & 97 & $\mathrm{Aa}$ & 2,45 & $\mathrm{Bb}$ & 1,97 & $\mathrm{Bc}$ & 3,13 & $\mathrm{Aa}$ \\
\hline$-0,2$ & 94 & $\mathrm{Aa}$ & 48 & $\mathrm{Bb}$ & 90 & $\mathrm{ABa}$ & 2,90 & $\mathrm{Cb}$ & 0,66 & $\mathrm{Cc}$ & 2,67 & $\mathrm{BCa}$ \\
\hline$-0,3$ & 59 & $\mathrm{Bb}$ & 33 & $\mathrm{Bc}$ & 89 & $\mathrm{ABa}$ & 2,16 & $\mathrm{Db}$ & 0,39 & $\mathrm{Cc}$ & 2,31 & $\mathrm{Ca}$ \\
\hline$-0,4$ & 20 & $\mathrm{Cb}$ & 0 & $\mathrm{Cc}$ & 81 & $\mathrm{ABCa}$ & 0,33 & $\mathrm{~Eb}$ & 0 & Dc & 1,62 & $\mathrm{Da}$ \\
\hline$-0,5$ & 0 & $\mathrm{Db}$ & 0 & $\mathrm{Cb}$ & 79 & $\mathrm{ABCa}$ & 0 & $\mathrm{~Eb}$ & 0 & $\mathrm{Db}$ & 0,98 & $\mathrm{Ea}$ \\
\hline$-0,6$ & 0 & $\mathrm{Db}$ & 0 & $\mathrm{Cb}$ & 70 & $\mathrm{Ca}$ & 0 & $\mathrm{~Eb}$ & 0 & $\mathrm{Db}$ & 0,83 & $\mathrm{Ea}$ \\
\hline$-0,7$ & 0 & $\mathrm{Da}$ & 0 & $\mathrm{Ca}$ & 0 & $\mathrm{Da}$ & 0 & $\mathrm{Ea}$ & 0 & $\mathrm{Da}$ & 0 & $\mathrm{Fa}$ \\
\hline$-0,8$ & 0 & $\mathrm{Da}$ & 0 & $\mathrm{Ca}$ & 0 & $\mathrm{Da}$ & 0 & $\mathrm{Ea}$ & 0 & $\mathrm{Da}$ & 0 & $\mathrm{Fa}$ \\
\hline$-0,9$ & 0 & $\mathrm{Da}$ & 0 & $\mathrm{Ca}$ & 0 & $\mathrm{Da}$ & 0 & $\mathrm{Ea}$ & 0 & $\mathrm{Da}$ & 0 & $\mathrm{Fa}$ \\
\hline$-1,0$ & 0 & $\mathrm{Da}$ & 0 & $\mathrm{Ca}$ & 0 & $\mathrm{Da}$ & 0 & $\mathrm{Ea}$ & 0 & $\mathrm{Da}$ & 0 & $\mathrm{Fa}$ \\
\hline $\mathrm{CV}(\%)=$ & 20,2 & & & & & & 17,36 & & & & & \\
\hline
\end{tabular}

*Valor de F significativo no nível de $5 \%$ de probabilidade; 'Médias seguidas por letras iguais, maiúsculas na coluna ou minúsculas na linha, não diferem entre si pelo teste de Tukey à $5 \%$ de probabilidade. 
observado por Fanti et al. (2004) para sementes de C. speciosa.

A porcentagem de germinação em sementes de $P$. alliacea reduz drasticamente a partir de $-0,4$ MPa quando o agente osmótico PEG foi utilizado, porém difere estatisticamente somente no potencial à $-0,6 \mathrm{MPa}$, resultados estes similares aos obtidos Rosa et al. (2005) que estudaram o estresse induzido por PEG em Ateleia glazioviana Baill., verificando que a partir de -0,4 MPa existiu decréscimo para a germinação, sendo mais acentuado para os potenciais à $-0,6$ e $-0,8 \mathrm{MPa}$.

Lima \& Torres (2009) observaram resultados semelhantes para a porcentagem de germinação de sementes de sementes de Zizyphus joazeiro Mart. à partir da concentração de $-0,4 \mathrm{MPa}$, com maior restrição da germinação quando utilizaram o agente osmótico $\mathrm{NaCl}$ em comparação ao PEG.

Entre os agentes osmóticos observa-se que à -0,2 $\mathrm{MPa}$ a porcentagem de germinação de $P$. alliacea é superior estatisticamente nos agentes osmóticos PEG e NaCl. A partir de -0,3 MPa a maior porcentagem de germinação é observada no PEG até $-0,6 \mathrm{MPa}$.

Neste trabalho os menores valores de porcentagem de germinação foram observados com a utilização do agente osmótico $\mathrm{CaCl}_{2}$ concordando com resultados de Fanti \& Perez (1998), que verificaram maior redução da porcentagem de germinação em sementes de Adenanthera pavonina L. nas soluções salinas, quando comparadas com soluções osmóticas em potenciais equivalentes.

O maior efeito inibitório das soluções de $\mathrm{CaCl}_{2}$ entre os agentes osmóticos pode estar associado ao fato do $\mathrm{Ca}^{2+}$ ser um importante mensageiro secundário da transdução de sinais, portanto, pequenas variações na concentração de $\mathrm{Ca}^{2+}$ alteram as atividades de enzimas associadas a este nutriente (Pallardy, 2008).

Com o agente osmótico PEG verificou-se maiores porcentagens de germinação, diferindo significativamente do $\mathrm{NaCl}$ e $\mathrm{CaCl}_{2}$ nos potenciais mais negativos. Este comportamento de acordo com Bradford (1995) e Braccini et al. (1996) é devido ao efeito da salinidade que não só dificulta a cinética de absorção da água, mas também facilita a entrada de íons em quantidade tóxica nas sementes em embebição.

Nos resultados do índice de velocidade de germinação observa-se interação entre os agentes osmóticos e os potenciais (Tabela 1).

O IVG sofreu redução significativa a partir de -0,1 MPa nos agentes osmóticos $\mathrm{NaCl}$ e $\mathrm{CaCl}_{2}$, enquanto no PEG a redução ocorreu à partir de $-0,3 \mathrm{MPa}$. Comparando os valores médios de IVG entre os agentes osmóticos observa-se que os maiores índices ocorreram no agente PEG em todos os potenciais avaliados (até -0,6 MPa). Entre os sais $\mathrm{CaCl}_{2}$ e $\mathrm{NaCl}$, o $\mathrm{CaCl}_{2}$ reduziu mais os valores de IVG nos potenciais entre $-0,1$ e $-0,4$ $\mathrm{MPa}$, enquanto nos demais potenciais não houve diferença significativa entre os sais.

Os resultados observados para sementes de $P$. alliacea são análogos aos resultados de Braga et al. (2009) que avaliando a germinação de sementes de Enterolobium schomburgkii (Benth.) submetidas a estresse salino verificaram menores valores de IVG quando utilizaram soluções de $\mathrm{CaCl}_{2}$ em comparação ao $\mathrm{NaCl}$. O comportamento das sementes de $P$. alliaceae é similar também para a espécie Ochroma pyramidale Cav. Ex Lam., em que ocorreu diferença significativa a partir do potencial à $-0,1 \mathrm{MPa}$ nas soluções de $\mathrm{NaCl}$, conforme descrito por Dalberto \& Braga (2013).

Assim como ocorreu redução da velocidade de germinação de $P$. alliacea, diferindo do controle conforme os potenciais osmóticos se tornaram mais negativos, na literatura observam-se resultados semelhantes para sementes de Ruta graveolens L. (Yamashita et al., 2009), Pimpinella anisum L. (Stefanello et al., 2006) e Zizyphus joazeiro Mart. (Lima \& Torres, 2009).

O IVG das sementes de $P$. alliacea diferiu significativamente em relação ao controle a partir da concentração de -0,3 MPa com o agente PEG e à partir de $-0,1 \mathrm{MPa}$ nos demais agentes osmóticos analisados, sendo que para a porcentagem de germinação obteve amplitude maior diferindo a partir dos potenciais -0,3, -0,2 e -0,6 MPa nos agentes $\mathrm{NaCl}, \mathrm{CaCl}_{2}$ e PEG, respectivamente. Resultados similares foram observados por Rollwagen \& Carvalho (2011) em sementes de Chamomilla recutita (L.) Rauschert onde a interferência da salinidade sobre o IVG foi mais drástica do que sobre a porcentagem de germinação, pois com o potencial de -0,2 MPa houve pequena redução do IVG que se acentuou até o potencial de -1,0 MPa.

$O$ efeito mais negativo do $\mathrm{CaCl}_{2}$ em relação aos outros agentes osmóticos sobre a velocidade do processo germinativo é devido provavelmente ao seu deslocamento para a superfície externa da membrana plasmática (juntamente com cátions metálicos) com o aumento da concentração de $\mathrm{Ca}^{2+} \mathrm{e}$ o subsequente prejuízo à permeabilidade da membrana e à integridade do conteúdo celular (Tobe et al., 2003), sendo o $\mathrm{Ca}^{2+}$ essencial na manutenção da integridade da membrana plasmática contribuindo para a diminuição do extravasamento de $\mathrm{K}^{+}$, o qual é responsável pela síntese de proteínas, amido e ativação de muitas enzimas no processo germinativo (Franco et al., 1999).

Sousa et al. (2008) avaliando o IVG de sementes de Plantago ovata Forsk. sob estresse osmótico induzido por $\mathrm{NaCl}, \mathrm{PEG}$ e $\mathrm{CaCl}_{2}$, 
verificaram menores valores em todos os potenciais para o agente osmótico PEG, em relação aos sais utilizados, diferindo dos resultados observados para $P$. alliacea L., onde no PEG ocorreram os maiores valores de IVG.

A utilização do agente osmótico PEG, quando comparado aos demais agentes osmóticos, provocou menor estresse na germinação de $P$. alliacea L., resultando em maior amplitude e velocidade da germinação para todos os potenciais avaliados. Este resultado de acordo com Fan \& Neumann (2004) pode estar relacionado ao fato do PEG ser quimicamente inerte, atóxico para as sementes, simulando a seca e não penetrando no tegumento devido ao tamanho de suas moléculas.

Pela Tabela 2, constata-se a interação entre agentes e potenciais osmóticos para o tempo médio de germinação (TMG) em sementes de $P$. Alliacea.

O TMG, no agente osmótico $\mathrm{NaCl}$ à $-0,1$ MPa não diferiu estatisticamente do controle $(0$ $\mathrm{MPa}$ ), sendo que a medida que os potenciais osmóticos tornaram-se mais negativos o TMG aumentou diferindo significativamente do controle e do potencial à $-0,1 \mathrm{MPa}$ (Tabela 2).

Os potenciais osmóticos simulados com $\mathrm{NaCl}$, à medida que se tornaram mais negativos promoveram um aumento de 1 a 7 dias do TMG. Rollwagen \& Carvalho (2011) verificaram efeito similar avaliando o estresse induzido por $\mathrm{NaCl}$ em sementes de C. recutita (L.) Rauschert observando um aumento de quatro para cerca de nove dias do TMG, até o potencial osmótico de -1,0 MPa.

Observou-se aumento progressivo do TMG de sementes de $P$. alliacea a partir de $-0,1 \mathrm{MPa}$ quando foi utilizado o agente $\mathrm{CaCl}_{2}$. O TMG diferiu estatisticamente a partir do potencial $-0,1 \mathrm{MPa}$ no agente osmótico PEG, com maior tempo médio no potencial à $-0,6 \mathrm{MPa}$ (25 dias) onde foi verificado 14 dias a mais que o controle.

No agente osmótico $\mathrm{NaCl}$ ocorreu TMG inferior aos demais agentes osmóticos, exceto no tratamento controle e no potencial de $-0,2 \mathrm{MPa}$ quando comparado ao PEG.

O atraso no início do processo germinativo com o aumento do estresse salino pode estar relacionado com a seca fisiológica induzida, pois quando existe aumento da concentração de sais no substrato de germinação, há redução do potencial osmótico e, consequentemente, redução do potencial hídrico, o que afeta a absorção de água pela semente alterando o processo germinativo podendo também elevar a níveis tóxicos a concentração de sais no embrião (Tobe et al., 2000).

$\mathrm{Na}$ Tabela 2 verifica-se a interação entre os agentes e potenciais osmóticos para o índice de sincronização $(\bar{E})$. No agente osmótico PEG não se verifica diferença estatística entre os potenciais osmóticos, mas no agente $\mathrm{CaCl}_{2}$ observou-se

TABELA 2. Tempo médio de germinação (TMG) e índice de sincronização (bits) de sementes de Petiveria alliacea L. expostas a diferentes agentes e potenciais osmóticos.

\begin{tabular}{|c|c|c|c|c|c|c|c|c|c|c|c|c|}
\hline \multirow{3}{*}{$\begin{array}{c}\text { Potencial osmótico } \\
\text { (MPa) } \\
0 \text { (controle) }\end{array}$} & \multicolumn{5}{|c|}{ TMG $^{1}$ (dias) } & & \multicolumn{6}{|c|}{$\overline{\mathrm{E}}^{1}$ (bits) } \\
\hline & \multicolumn{2}{|c|}{$\mathrm{NaCl}$} & \multicolumn{2}{|c|}{$\mathrm{CaCl}_{2}$} & \multicolumn{2}{|c|}{ PEG } & \multicolumn{2}{|c|}{$\mathrm{NaCl}$} & \multicolumn{2}{|c|}{$\mathrm{CaCl}_{2}$} & \multicolumn{2}{|c|}{ PEG } \\
\hline & 11 & $\mathrm{Aa}$ & 11 & $\mathrm{Aa}$ & 11 & $\mathrm{Aa}$ & 2,1 & $\mathrm{BCa}$ & 2,1 & $\mathrm{Aa}$ & 2,1 & $\mathrm{Aa}$ \\
\hline$-0,1$ & 12 & $\mathrm{Aa}$ & 16 & $\mathrm{Bb}$ & 19 & $\mathrm{Bc}$ & 2,0 & $\mathrm{Ba}$ & 2,7 & $\mathrm{Bb}$ & 2,6 & $A b$ \\
\hline$-0,2$ & 18 & $\mathrm{Ba}$ & 22 & $\mathrm{Cb}$ & 19 & $\mathrm{Ba}$ & 2,9 & $\mathrm{Da}$ & 2,5 & $A B b$ & 2,5 & $A b$ \\
\hline$-0,3$ & 17 & $\mathrm{Ba}$ & 26 & $\mathrm{Dc}$ & 20 & $\mathrm{Bb}$ & 2,5 & CDab & 2,4 & $\mathrm{ABa}$ & 2,9 & $A b$ \\
\hline$-0,4$ & 18 & $\mathrm{Ba}$ & - & & 21 & $\mathrm{Bb}$ & 1,4 & $\mathrm{Aa}$ & - & & 2,9 & $\mathrm{Ab}$ \\
\hline$-0,5$ & - & & - & & 25 & C & - & & - & & 2,3 & A \\
\hline$-0,6$ & - & & - & & 25 & C & - & & - & & 2,6 & A \\
\hline$-0,7$ & - & & - & & - & & - & & - & & - & \\
\hline$-0,8$ & - & & - & & - & & - & & - & & - & \\
\hline$-0,9$ & - & & - & & - & & - & & - & & - & \\
\hline$-1,0$ & - & & - & & - & & - & & - & & - & \\
\hline $\mathrm{CV}(\%)=$ & & & & & & & & & 18 , & & & \\
\hline
\end{tabular}

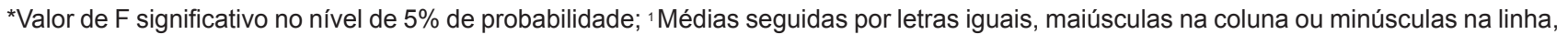
não diferem entre si pelo teste de Tukey à $5 \%$ de probabilidade. 
maior sincronização do processo germinativo no controle quando comparado ao potencial -0,1 MPa. Para o agente $\mathrm{NaCl}$ verificou-se maior sincronia da germinação no potencial $-0,4 \mathrm{MPa}$. $\mathrm{O}$ resultado observado no potencial à $-0,4 \mathrm{MPa}$ é devido ao reduzido número de sementes germinadas $(\mathrm{Nt}=5)$.

Pode-se constatar entre os agentes osmóticos analisados diferença estatística para a sincronização da germinação, obtendo para o agente $\mathrm{NaCl}$ maior sincronização da germinação, não diferindo apenas no potenciais à $-0,3 \mathrm{MPa}$ do agente $\mathrm{CaCl}_{2}$. Essa maior sincronização expressa a menor entropia informacional ou incerteza associada à distribuição de frequências (Labouriau, 1983; Labouriau \& Agudo, 1987).

Rollwagen \& Carvalho (2011) avaliando o estresse induzido por $\mathrm{NaCl}$ em sementes de $C$. recutita (L.) Rauschert observaram aumento da entropia a medida que aumentou a concentração osmótica, resultados estes similares aos obtidos para $P$. alliacea.

Para a frequência relativa da germinação nos potenciais e agentes osmóticos analisados não se obteve o padrão da distribuição no gráfico em potenciais acima de -0,5, -0,4 e -0,7 MPa para os agentes osmóticos $\mathrm{NaCl}, \mathrm{CaCl}_{2}$ e PEG, respectivamente, pois nos mesmos não se observou germinação (Figura 1).

$\mathrm{Na}$ Figura 1 verifica-se nos potenciais menos restritivos $(0$ e $-0,1 \mathrm{MPa})$ nos agentes osmóticos analisados que o padrão de distribuição dos polígonos apresenta caráter unimodal e menores valores de TMG. À medida que os potenciais osmóticos ficam mais negativos a distribuição da germinação aumenta ao longo do tempo, conferindo um caráter de distribuição polimodal. Os valores de TMG variaram entre 11 dias (0 MPa) e 26 dias (-0,3 MPa no $\mathrm{CaCl}_{2}$ ) indicando aumento na distribuição do tempo médio para germinação das sementes.

Lemes \& Lopez (2010) verificaram em sementes de Ceiba speciosa St. Hil. submetidas a estresse salino que os picos das frequências relativas diárias da germinação se deslocaram para tempos maiores de germinação à medida que aumentou a concentração dos potenciais osmóticos, resultados estes similares ao obtidos neste trabalho para $P$. alliacea.

Bewley \& Black (1994) afirmam que a maior distribuição da germinação no tempo, em resposta às condições de estresse, ocorre porque nem todas as sementes apresentam a mesma qualidade fisiológica frente ao estresse. Fato este que pode beneficiar as sementes no ambiente possibilitando maior probabilidade de superação ao estresse devido à germinação assincronizada.

Concentrações osmóticas mais negativas mantiveram maior número de sementes de $P$. alliacea quiescentes. Segundo Vidal \& Bauman (1996) esta característica da espécie pode ter significado ecológico ligado à sua sobrevivência,
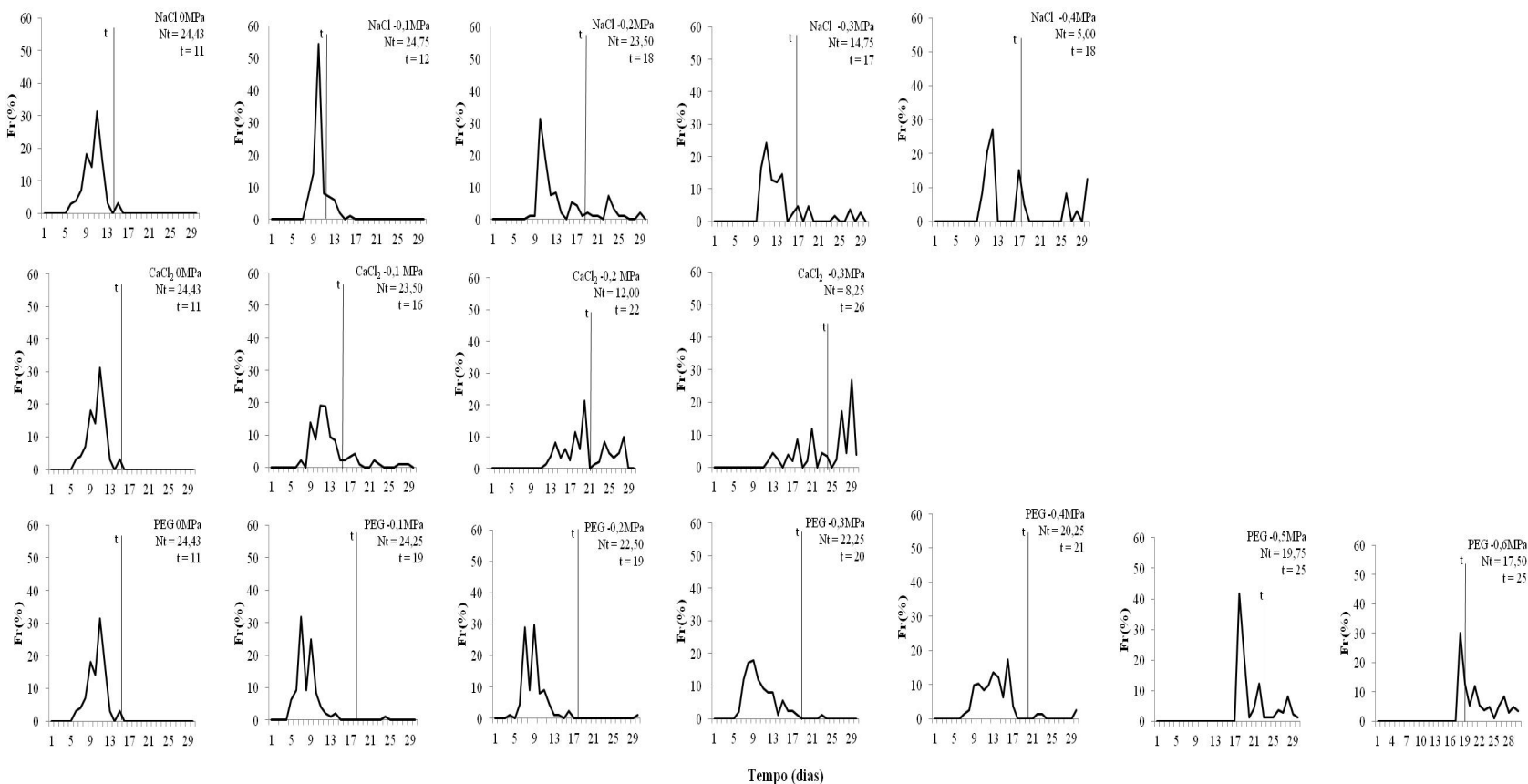

FIGURA 1. Frequências relativas (Fr) da germinação de sementes de Petiveria alliacea L., em função de diferentes potenciais e tipos de agentes osmóticos. $\mathrm{Nt}=$ número total de sementes germinadas; $\mathrm{t}=$ tempo médio de germinação. 
pois previne o desenvolvimento de plântulas em solos sem recursos suficientes para suportar o crescimento subsequente.

Os resultados obtidos em sementes de $P$. alliacea, especialmente no agente osmótico PEG, indicam que as sementes desta espécie possuem pouca exigência de água para germinação, tolerando potenciais osmóticos até -0,6 MPa. Esta tolerância pode ser considerada elevada em relação ao comportamento de outras espécies que apresentam reduções significativas da porcentagem de germinação, como a partir de -0,5 MPa em sementes de Bowdichia virgiloides Kunth (Silva et al., 2001), à -0,1 MPa em sementes de Schizolobium amazonicum Huber ex Ducke (Braga et al., 2008), entre -0,1 e -0,4 MPa em sementes de Adenanthera pavonina L. (Fanti \& Perez, 1998) e -0,4 MPa em sementes de Erythrina falcata Benth (Pelegrini et al., 2013). Este elevado limite de tolerância ao estresse hídrico confere à $P$. alliacea caráter adaptativo, propiciando alta capacidade de estabelecimento em campo em condições de baixo regime hídrico.

Pode-se considerar que Petiveria alliacea L. apresenta maior potencial germinativo em potenciais osmóticos menos negativos (controle e $-0,1 \mathrm{MPa}$ ), com maior tolerância ao estresse com PEG. O agente osmótico $\mathrm{CaCl}_{2}$ foi o mais restritivo a germinação considerando todas as variáveis analisadas. Em potenciais osmóticos mais negativos que $-0,4 ;-0,5$ e - $0,7 \mathrm{MPa}$, respectivamente para os agentes $\mathrm{CaCl}_{2}, \mathrm{NaCl}$, e PEG, não ocorre germinação em sementes de Petiveria alliacea L..

O estresse osmótico em sementes de Petiveria alliacea L. reduziu a porcentagem e velocidade de germinação e aumentou a polimodalidade, o tempo médio de germinação e o índice de sincronização da germinação com a redução dos potencias osmóticos.

\section{REFERÊNCIAS}

BEWLEY, J.D.; BLACK, M. Seeds - physiology of development and germination. New York: Plenum Press, 1994. 275p.

BRACCINI, A.L. et al. Germinação e vigor de sementes de soja sob estresse hídrico induzido por soluções de cloreto de sódio, manitol e polietileno glicol. Revista Brasileira de Sementes, v.18, n.1, p.10-16, 1996.

BRADFORD, K.J. Water relations in seed germination. In: KIGEL, J.; GALILI, G. (Eds.). Seed development and germination. New York: Marcel Dekker, 1995. 872p.

BRAGA, L.F. et al. Efeito da disponibilidade hídrica do substrato na qualidade fisiológica de sementes de feijão. Revista Brasileira de Sementes, v.21, n.2, p.95-102, 1999.

BRAGA, L.F. et al. Germinação de sementes de pinhocuiabano sob deficiência hídrica com diferentes agentes osmóticos. Scientia Forestalis, v.36, n.78, p.157-163,
2008.

BRAGA, L.F. et al. Germinação de sementes de Enterolobium schomburgkii (Benth.) Benth. submetidas a estresse salino e aplicação de poliamina. Revista Brasileira de Plantas Medicinais, v.11, n.1, p.63-70, 2009.

BRASIL. Ministério da Agricultura e da Reforma Agrária. Regras para análise de sementes. Brasília: SNDA/ DNDV/CLAV, 2009. 365p.

CAMARGO, M.T.L.A. Contribuição Etnofarmacobotânica ao estudo de Petiveria alliacea L. - Phytolacaceae("amansa-senhor") e a atividade hipoglicemiante relacionada a transtornos mentais. Dominguezia, v.23, n.1, p.21-27, 2007.

CANO, J.H.; VOLPATO, G.J. Herbal mixtures in the traditional medicine of Eastern Cuba. Etnopharmacology, v.90, n.1, p.293, 2004.

CARDOSO, V.J.M. Germinação. In: KERBAUY, G.B. (Ed.). Fisiologia vegetal. Rio de Janeiro: Guanabara Koogan, 2004. 408p.

CARVALHO, N.M.; NAKAGAWA, J. Sementes: ciência, tecnologia e produção. 4.ed. Jaboticabal: FUNEP, 2000. 588p.

DALBERTO, D.S.; BRAGA, L. F.. Estresse osmótico na germinação de sementes de Ochroma pyramidale (Cav. Ex Lam.) Urb. (Malvaceae). Científica, v.41, n.2, p.99-110, 2013.

DICKMAN, L. et al. Comportamento de sementes de girassol (Helianthus annuus L.) submetidas a estresse salino. Revista de Ciências Agro-Ambientais,v.3, n.1, p.65- 75, 2005.

FAN, L.; NEUMANN, P.M. The spatially variable inhibition by water deficit of maize root growth correlates with altered profiles of proton flux and cell wall $\mathrm{pH}$. Plant Physiology, v.135, n.4, p.2291-2300, 2004.

FANTI, S.C.; PEREZ, S.C.J.G.A. Efeitos do estresse hídrico, salino e térmico no processo germinativo de sementes de Adenanthera pavonina L. Revista Brasileira de Sementes, v.20, n.1, p.167-177, 1998.

FANTI, S.C.; PEREZ, S.C.J.G.A. Processo germinativo de sementes de paineira sob estresses hídrico e salino. Pesquisa Agropecuária Brasileira, v.39, n.9, p.903909, 2004.

FERREIRA, D, F. Sisvar: um sistema computacional de análise estatística. Ciências agrotécnicas, v.35, n.6, p.1039-1042, 2011.

FRANCO, O.L. et al. Effects of $\mathrm{CaCl}_{2}$ on the growth and osmoregulator accumulation in $\mathrm{NaCl}$ stressed cowpea seedlings. Revista Brasileira de Fisiologia Vegetal, v.11, n.1, p.145-151, 1999.

GUPTA, M.P. 270 Plantas Medicinales Iberoamericanas. Santa Fé de Bogotá - Colômbia: Programa Iberoamericano de Ciencia y Tecnología para el desarrollo CYTED-SECAB. 1995. 607p.

$\mathrm{KIM}$, S. et al. Antibacterial and antifungal activity of sulfurcontaining compounds from Petiveria alliacea $\mathrm{L}$. Journal of Ethnopharmacology, v.104, n.1, p.188-192, 2006.

LABOURIAU, L.G. A germinação das sementes. Washington: Secretaria da OEA, 1983. 173p.

LABOURIAU, L.G.; AGUDO, M. On the physiology of germination in Salvia hispanica L. Temperature effects. Anais da Academia Brasileira de Ciências, v.59, n.1, p.37-56, 1987. 
LABOURIAU, L.G.; VALADARES, M.E.B. On the germination of seeds Calotropis procera (Ait.) Ait.f. Anais da Academia Brasileira de Ciências, v.48, n.2, p.263-284, 1976.

LABOURIAU, L.G.; PACHECO, A. On the frequency of isothermal germination in seeds of Dolichos biflorus $\mathrm{L}$. Plant and Cell Physiology, v.19, n.3, p.507-512, 1978.

LARCHER, W. Ecofisiologia Vegetal. São Carlos: Rima, 2000. 531p.

LEMES, E.Q.; LOPES, J.C. Freqüência Relativa da germinação de sementes de Paineira (Ceiba speciosa St. Hil.) sob estresse salino. XIV Encontro Latino Americano de Iniciação Científica INIC; X Encontro Latino Americano de Pós Graduação EPG; IV Encontro Latino Americano de Iniciação Científica Junior INIC Jr, Anais... São José dos Campos - SP, p.1-4, 2010.

LIMA, B.G.; TORRES, S.B. Estresses hídrico e salino na germinação de sementes de Zizyphus joazeiro Mart. (Rhamnaceae). Revista Caatinga, v.22, n.4, p.93-99, 2009.

MAGUIRE, J.D. Speed of germination-aid in selection and evaluation for seedling emergence and vigour. Crop Science, v.2, n.2, p.176-177, 1962.

MARCOS FILHO, J. Fisiologia de sementes de plantas cultivadas. Piracicaba: FEALQ, 2005. 495p.

MORAES, G.A.F.; MENEZES, N.L. Desempenho de sementes de soja sob condições diferentes de potencial osmótico. Ciência Rural, v.33, n.2, p.219-26, 2003.

NASR, S.M.H. et al. Effect of salt stress on germination and seedling growth of Prosopis juliflora (Sw.). New Forests, v.42, n.1, p.9265-9269, 2011.

NOGUEIRA, R.J.M.C.; et al. Alterações na resistência à difusão de vapor das folhas e relações hídricas em aceroleiras submetidas a déficit de água. Revista Brasileira de Fisiologia Vegetal, v.13, n.1, p.75-87, 2005.

PALLARDY, D.S.G. Molecules Physiology of Woody Plants (Third Edition). San Diego: Academic Press, 2008. 377p.

PELEGRINI, L.L. et al. Efeito do estresse hídrico simulado com $\mathrm{NaCl}$, manitol e PEG (6000) na germinação de sementes de Erythrina falcata Benth. Ciência Florestal, v.23, n.2, p.511-519, 2013.

PEREIRA, M.R.R. et al. Influência do estresse hídrico e salino na germinação de Urochloa decumbens e Urochloa ruziziensis. Bioscience Journal, v.28, n.4, p.537-545, 2012.

ROLLWAGEN, D.G.; CARVALHO, R.I.N. Qualidade fisiológica de sementes de camomila [Chamomilla recutita (L.) Rauschert] após envelhecimento acelerado e estresse salino. Revista Brasileira de Plantas Medicinais, v.13, n.2, p.139-145, 2011.

ROSA, L.S. et al. Avaliação da germinação sob diferentes potenciais osmóticos e caracterização morfológica da semente e plântula de Ateleia glazioviana Bail (Timbó). Revista Cerne, v.11, n.1, p.306-314, 2005.

REHMAN, S. et al. The effect of sodium chloride on germination and the potassium and calcium contents of Acacia seeds. Seed Sciente and Technology, v.25, n.1, p.45-57, 1996.

SILVA, L.M.M. et al. Seed germination of Bowdichia virgilioides Kunth, under water stress. Revista Brasileira de Engenharia Agrícola e Ambiental, v.5, n.1, p.115-118, 2001.

SOUSA, M.P. et al. Estresses hídrico e salino no processo germinativo das sementes de Plantago ovata Forsk. (Plantaginaceae). Revista Árvore, v.32, n.1, p.33-38, 2008.

STEFANELLO, R. et al. Influência da luz, temperatura e estresse hídrico na germinação e no vigor de sementes de anis. Revista Brasileira Agrociência, v.12, n.1, p.45-50, 2006.

SUN, W.Q.; LEOPOLD, A.C. Cytoplasmic vitrification and survival of anhydrobiotic organisms. Comparative Biochemistry and Physiology, v.117A, n.3, p.327333, 1997.

TAIZ, L.; ZEIGER, E. Fisiologia vegetal. 3.ed. Porto Alegre: Artmed, 2004. 719p.

TOBE, K. et al. Seed germination and radicle growth of a halophyte, Kalidium caspicum (Chenopodiaceae). Annals of Botany, v.85, n.3, p.391-6, 2000.

TOBE, K. et al Alleviatory effects of calcium on the toxicity of sodium, potassium and magnesium chlorides to seed germination in three nonhalophytes. Seed Science Research, v.13, n.1, p.47-54, 2003.

VIDAL, R.A.; BAUMAN, T.T. Surface wheat (Triticum aestivum) residues, giant foxtail (Setaria faberi), and soybean (Glycine max) yield. Weed Science, v.44, n.4, p.939-943, 1996.

VILLELA, F.A. et al. Tabela de potencial osmótico em função da concentração de polietileno glicol 6000 e da temperatura. Pesquisa Agropecuária Brasileira, V.26, n.11/12, p.1957-1968, 1991.

YAMASHITA, O.M. et al. Fatores que afetam a germinação de sementes e emergência de plântulas de arruda (Ruta graveolens L.). Revista Brasileira de Plantas Medicinais, v.11, n.2, p.202-208, 2009. 